\title{
Cadastro Ambiental Rural (CAR) e municípios costeiros maranhenses: análise dos dados autodeclarados
}

O CAR é um instrumento de planejamento de gestão pública, criado por meio do mais recente Código Florestal Brasileiro (Lei Federal n. 12.651/2012). Trata-se de um registro eletrônico - obrigatório - das informações ambientais das propriedades/imóveis rurais de todo o território brasileiro, construindo uma base de dados a nível nacional para planejamento territorial e estratégias de controle, monitoramento e combate ao desmatamento do país. Alguns estudos preliminares vêm almejando analisar algumas destas informações prestadas na plataforma; entretanto, recorrentes em pequenas áreas e, ainda, com pouca atenção às áreas costeiras do país, que apresentam relevante impacto socioeconômico e ambiental. Diante disso, o objetivo da pesquisa foi realizar uma análise dos registros de CAR nos municípios costeiros do Estado do Maranhão (MCMa) com base em metadados independentes, fornecidos por órgãos oficiais, elencando as incongruências das informações inseridas no SiCAR e discutindo seus entraves. Para tanto, os registros dos cadastros foram armazenados e processados em um ambiente SIG (Sistema de Informações Geográficas), sendo cotejado com dados espaciais do MMA, IBGE, ANA, SEMA/MA e Embrapa. Como principais resultados: $25 \%$ das áreas dos imóveis estão sobrepostas, mais de 2 milhões de hectares (ha) passiveis de cadastramento não foram registrados; as áreas de altitude superior a $1800 \mathrm{~m}$ e de declividade maior que 45 graus foram fidedignas à realidade; enquanto que, para áreas de manguezais e restingas, houve baixo percentual de cadastro, as duas menores que $6 \%$ do esperado; já quanto à hidrografia, foram aferidas falhas em APPs que deveriam ser contínuas, de geometria suspeita e de faixas discrepantes quando numa análise circunvizinha.

\section{Rural Environmental Registry (CAR) and coastal municipalities of Maranhão: self-declared data analysis}

\begin{abstract}
The CAR is a public management planning instrument, created through the most recent Brazilian Forest Code (Federal Law No. 12,651 / 2012). It is a mandatory electronic registration of environmental information from rural properties / properties throughout Brazil, building a national database for territorial planning and strategies for controlling, monitoring and combating deforestation in the country. Some preliminary studies have aimed to analyze some of this information provided in the platform; however, recurring in small areas and with little attention to the coastal areas of the country, which have significant socioeconomic and environmental impact. Given this, the objective of the research was to perform an analysis of CAR records in the coastal municipalities of the State of Maranhão (MCMa) based on independent metadata, provided by official agencies, listing the inconsistencies of the information entered in SiCAR and discussing its obstacles. To this end, the records of the records were stored and processed in a GIS environment (Geographic Information System), being collated with spatial data from MMA, IBGE, ANA, SEMA / MA and Embrapa. Main results: $25 \%$ of the real estate areas are overlapping, more than 2 million hectares (ha) subject to registration were not registered; areas with altitudes above $1800 \mathrm{~m}$ and slopes greater than 45 degrees were true to reality; while for mangrove and restingas areas, there was a low percentage of registration, both less than $6 \%$ of expected; As for hydrography, faults in PPAs that should be continuous, of suspicious geometry and of discrepant bands were measured when in a surrounding analysis.
\end{abstract}

Keywords: Brazilian Forest Code; Maranhão recesses; Maranhão; SIG.

Topic: Planejamento, Gestão e Políticas Públicas Ambientais

Reviewed anonymously in the process of blind peer.
Received: 27/06/2019

Approved: 28/07/2019

Victor Nathan Lima da Rocha (i)

Universidade Federal da Paraíba, Brasil

http://lattes.cnpq.br/5022112931485478

http://orcid.org/0000-0002-6736-2538

victornathan.eng@gmail.com

André Luís Silva dos Santos (iD)

Instituto Federal do Maranhão, Brasil

http://lattes.cnpq.br/8177263015165738

http://orcid.org/0000-0002-9590-6686

andresantos@ifma.edu.br

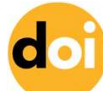

DOI: 10.6008/CBPC2179-6858.2019.004.0025
Referencing this:

ROCHA, V. N. L.; SANTOS, A. L. S.. Cadastro Ambiental Rural (CAR) e municípios costeiros maranhenses: análise dos dados autodeclarados. Revista Ibero-Americana de Ciências Ambientais, v.10, n.4, p.328336, 2019. DOI: http://doi.org/10.6008/CBPC2179$\underline{6858.2019 .004 .0025}$ 


\section{INTRODUÇÃO}

O CAR é um instrumento de planejamento de gestão pública, criado por meio do mais recente Código Florestal, trata-se de um registro eletrônico - obrigatório - com até 18 camadas (layers) de informações ambientais (área do imóvel, Áreas de Preservação Permanente de cursos d'água/APPs, área consolidada, reserva legal (RL), vegetação nativa remanescente, restinga, manguezal, veredas, hidrografia, servidão administrativa, pousio, declividade superior a $45^{\circ}$, topo de morro, altitude superior a 1800 , de uso restrito, nascentes, banhado e borda de chapadas) das propriedades/imóveis rurais de todo o território brasileiro, construindo uma base de dados a nível nacional para planejamento territorial e estratégias de controle, monitoramento e combate ao desmatamento do país (MMA, 2015; BRASIL, 2012a).

Historicamente, foi criado em 2012 pelo supracitado dispositivo legal e regulamentado pelo Decreto Federal no 7.830 no mesmo ano (BRASIL, 2012b), criando o SiCAR, que trata de um sistema eletrônico georreferenciado, que mantém um banco de dados das informações autodeclaradas dos imóveis rurais, de caráter jurídico que substitui a até então obrigatoriedade de registro cartorário. Seu prazo máximo de adesão inicial era até um ano pós-implantado - 17 de outubro de 2013 (BRASIL, 2012b), posteriormente prorrogado diversas vezes pelo executivo federal, com o último ato em 2019 - MP 884/2019, sem prazo determinado, deixando a deriva o limite de regularização destes imóveis (BRASIL, 2019).

Seu mais recente Boletim Informativo/abril-2019 (SBF, 2019) apresenta que o país apresentou uma área total cadastrada superior à passível de cadastro (base Censo Agropecuário 2006 do IBGE). Quanto ao estado do Maranhão, a publicação retrata que a área passível de cadastro é de $13.033 .568,00 h a$, enquanto 21.568.681,00ha foram cadastrados, pressupondo sobreposição de imóveis registrados, fonte de uso indevido da plataforma.

Nessa linha de pensamento, o CAR é fonte de dúvidas e incongruências, Tupiassuet et al. (2017) aborda que, em estudo no Estado do Pará, o instrumento vem sido utilizado indevidamente, constituindo numa "nova ferramenta de grilagem e culmina por não atender o objetivo ambiental inicialmente almejado", além de outras de óticas fundiária e tributária.

Outro aspecto sensível do cadastro é quanto à precisão do registro e à veracidade das informações prestadas, que por se tratar de declaratórias, pode mascarar áreas protegidas (APPs e RLs) que foram suprimidas sem a devida autorização e/ou anistiada (posterior a 22/07/2008) ou de quantitativo duvidoso. Neste tocante, o Módulo de Análise encontra-se em processo de implementação, mas é presumível que consistirá numa fase morosa e com maior demanda de corpo técnico capacitado pelos órgãos ambientais responsáveis.

Em atenção a sua importância, pesquisas têm discutido o avanço de adesão ao CAR em estudos de casos, geralmente em nível municipal (BRUGNARA et al., 2016; STRAPASSON JUNIOR, 2016; PANTOJA et al., 2015) e de órgão oficiais e ONGs para o contexto nacional, sobretudo na Amazônia (ABIOVE, 2016; INOVACAR, 2016, 2015, 2014). Não obstante, pouca atenção tem sido dada em regiões litorâneas e costeiras, apesar de se tratar de ambientes objetos de gestão e instrumentos próprios, face as suas peculiaridades, 
como no caso do Plano Nacional de Gerenciamento Costeiro - PNCG, que dispõe sobre regras de uso e ocupação da zona costeira e estabelece critérios de gestão da orla marítima (BRASIL, 2004).

O PNCG abrange a zona costeira brasileira em uma faixa marítima e outra terrestre, esta última conceituada como o espaço compreendido pelos limites dos Municípios - defrontantes ou não com o mar que sofrem influência direta dos fenômenos ocorrentes na zona costeira (BRASIL, 2004, 1988). No recorte estadual, a Lei Estadual no 5.405/1992, destaca por meio do seu art. 132 que "A Zona Costeira é espaço físicoterritorial especialmente protegido, objeto de gerenciamento costeiro com o fim de planejar, disciplinar, controlar e fiscalizar as atividades, empreendimentos e processos que causem ou possam causar degradação ambiental, observada a legislação Estadual e Federal" (MARANHÃO, 1992).

Insta destacar a importância destes ambientes costeiros, uma vez que se trata de um mosaico de diferentes paisagens e ecossistemas, como manguezais, restinga, regiões tropicais úmidas, dunares, lagunares, praias oceânicas, reentrâncias, estuários, dentre outros; de grande relevância socioeconômica e ambiental, contudo, de elevada fragilidade ambiental (TEIXEIRA et al., 2009; EL-ROBRINI et al., 2006; PINHEIRO, 2002). Nesta perspectiva, Pinheiro (2002) pondera que "as faixas litorâneas, pela sua singularidade ambiental, são um dos ambientes naturais mais complexos, em função de sua localização de contato direto entre o oceano, o continente e a atmosfera", corroborando, portanto, na necessidade de estudos que analisam a implementação de instrumentos de gestão territorial em ambientes costeiros.

Face ao exposto, o objetivo da presente pesquisa foi realizar uma avaliação das informações constantes nos registros de CAR nos municípios costeiros do Estado do Maranhão, destacando incoerências e consonâncias dos registros, cotejando-as com informações espaciais obtidas em distintos órgãos ambientais.

\section{METODOLOGIA}

\section{Área de estudo}

A região dos Municípios Costeiros do Maranhão (ou Municípios Costeiros Maranhenses, doravante denominada $\mathrm{MCMa}$ ) é formada pela união de 35 unidades político-administrativas do Estado do Maranhão (figura 1), região Nordeste do Brasil, totalizando 35.111,305km². A Lei Estadual no 5.405/1992 define a Zona Costeira Maranhense (ZCMa) como "o espaço físico-territorial, objeto do gerenciamento costeiro, denominado Zona Costeira do Estado, abrange a totalidade dos municípios litorâneos do Estado, e as costeiras" (MARANHÃO, 1992).

A ZCMa, aqui definida, está inserida no ZCEM (Zoneamento Costeiro e Estuarino do Maranhão) e, uma vez que os registros do CAR são realizados na totalidade do munícipio, foi então definida a área de estudo como os MCMa. Os MCMa apresentam diferentes tipos de paisagens e ecossistemas, característica comum de áreas litorânea, tais como mangues, praias, reentrâncias, cordões dunares, lacustres, dentre outras; denotando com isso sua exuberante biodiversidade (ICMBIO, 2018; MARTINS et al., 2011, EL-ROBRINI et al., 2006). 


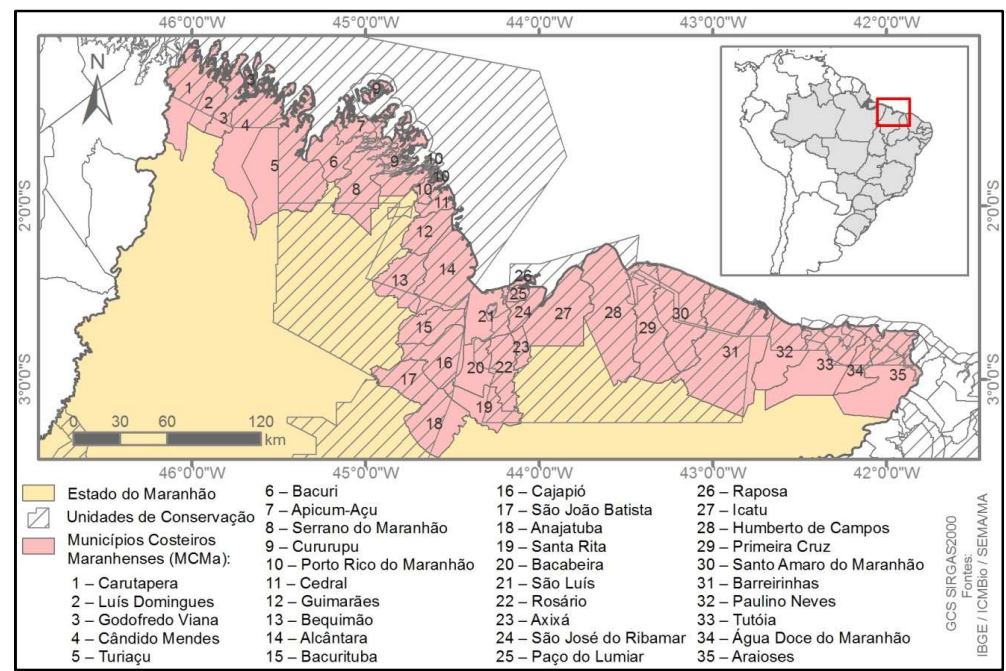

Figura 1: Localização geográfica dos Municípios Costeiros Maranhenses (MCMa), Estado do Maranhão, Brasil.

\section{Aquisição e processamento dos dados}

Os arquivos vetoriais dos registros CAR nos $35 \mathrm{MCMa}$ foram obtidos na plataforma digital do Sistema Florestal Brasil (SFB) denominada SiCAR (Sistema Nacional de Cadastro Ambiental Rural), gratuitamente, em 22 de agosto de 2018, na aba de Consulta Pública. Dentre todas as camadas de informações ambientais disponíveis dos imóveis registrados, na presente pesquisa foram utilizadas as seguintes áreas: do imóvel, manguezal, restinga, altitude superior a $1800 \mathrm{~m}$, declividade maior que $45^{\circ}, \mathrm{APP}$ (cursos d'água) e hidrografia.

Tabela 1: Resumo dos dados utilizados na pesquisa.

\begin{tabular}{|c|c|c|}
\hline Informação & Fonte & Data / Ano \\
\hline Registros CAR & SFB/SiCAR & $22 / 08 / 2018$ \\
\hline Áreas protegidas (UC, TI, outras) & MMA, SEMA/MA & IBGE \\
\hline Áreas urbanas & ANA & 2017 \\
\hline Hidrografia & MMA, IBGE & 2010 \\
\hline Manguezal e Restingas & IBGE, Embrapa & 2013 \\
\hline Altitude e declividade & 2005 \\
\hline
\end{tabular}

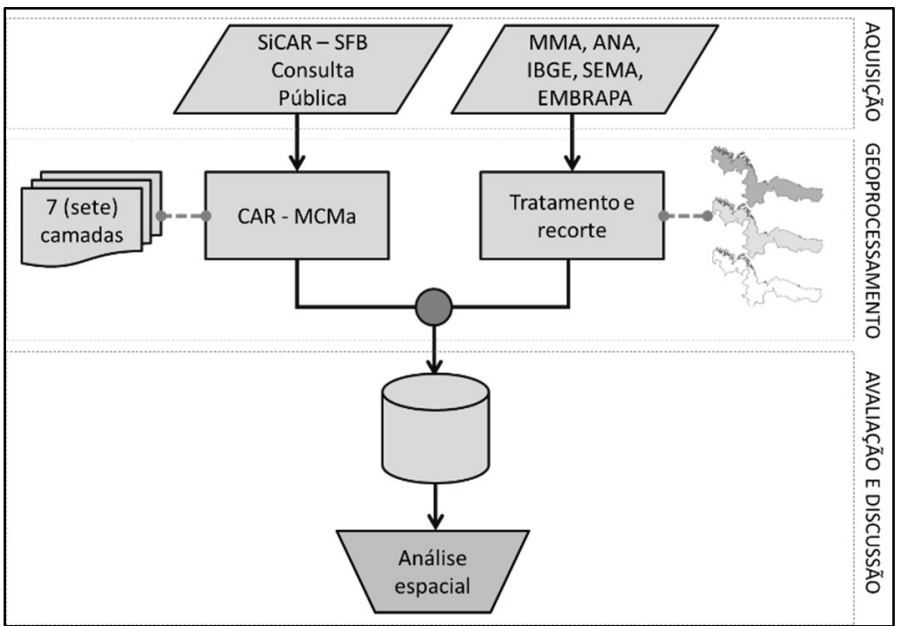

Figura 2: Fluxograma das etapas metodológicas realizadas na pesquisa.

Já para o cotejo dos dados utilizados na análise de consistência das informações foram utilizados arquivos vetoriais e matriciais de diferentes órgãos ambientais, como do Ministério do Meio Ambiente (MMA), Agência Nacional de Águas (ANA), Instituto Brasileiro de Geografia e Estatística (IBGE), Secretaria Estadual de Meio Ambiente e Recursos Naturais do Maranhão (SEMA/MA) e Empresa Brasileira de Pesquisa 
Agropecuária (Embrapa). As variáveis, órgão e data de publicação encontram-se na tabela 1. A figura 2 apresenta o fluxograma das etapas metodológicas realizadas durante a pesquisa, dividida em três fases: Aquisição dos dados, Geoprocessamento em ambiente SIG (Sistema de Informações Geográficas) e Avaliação e Discussão dos produtos.

Posterior ao geoprocessamento, todos os dados foram copilados num banco de dados único, permitindo a análise espacial de diferentes camadas de informações e fontes circunstancialmente. Aplicando técnicas de sobreposição (overlay mapping), contribuindo na discussão de interseções, proximidades e conflitos de informações.

\section{RESULTADOS E DISCUSSÃO}

Nos 35 municípios foram evidenciados 2633 registros de CAR, sendo que alguns foram descartados devido à condição de cancelado por decisão administrativa (CA), resultando em 2620 registros em situação de aguardando análise técnica (AT) ou analisado por filtro automático (PE). Número baixo quando comparado ao total do Estado com pouco mais de 107 mil imóveis (SBF, 2019).

Esse conjunto engloba uma área de 1.272.617,697 hectares (ha) registrada nos MCMa, entretanto, na análise de sobreposição de dados, 324.131,132ha foram declarados mais de uma vez, ou seja, equivalente a pouco mais de $25 \%$ da área cadastrada apresenta inconformidade no sistema. Isso pode ser decorrente de fracionamento intencional do imóvel, conflitos de regularização fundiária, imprecisões no momento cadastral, dentre outros; conforme é ilustrado na figura 3.

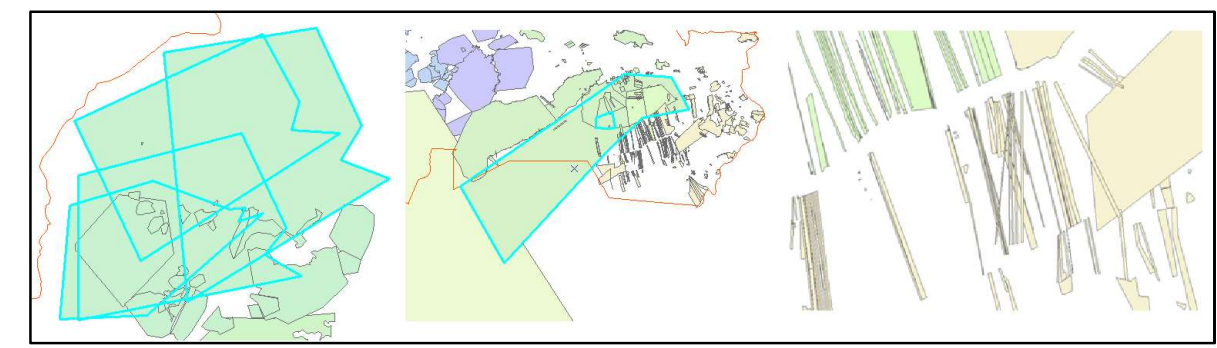

Figura 3: Entraves dos registros CAR nos MCMa (sobreposição, fracionamento e erros).

Esse aspecto é de suma importância, uma vez que é sabido que um dos principais estímulos de adesão ao registro é a exigência para fins de empréstimos e incentivos financeiros. Assim, sugerindo fracionamento da área total para declinar de exigências legais e/ou se incorporar em perfis de incentivos. Dificultando a validação dos dados, pois necessitará de uma análise de vizinhança e, por consequente, na regularização ambiental do imóvel.

Outro ponto a destacar, segundo os dados utilizados, é o total de área cadastrada em relação à área apta declarável no SiCAR. Essa última trata-se da MCMa descartando áreas urbanas e áreas públicas protegidas (Parques Estaduais e Federais, Resex, Floresta Públicas, Terras Indígenas e outras), conforme Figura 4.

Evidenciou-se, a priori, que apenas 32\% da área dos MCMa foi cadastrada, carecendo ainda de pouco mais de 2 milhões de hectares ser declarado (de agora em diante denominada de área declarável). Não 
obstante, cabe frisar que outras áreas de dominialidade do Estado do Maranhão e da União não foram consideradas em virtude da indisponibilidade dos dados espacializados (vetorizadas), sugerindo possível superestimação da área aqui classificada como declarável. Porém, com certa folga, é possível concluir que ainda existe um passivo considerável de áreas não informadas no SiCAR.

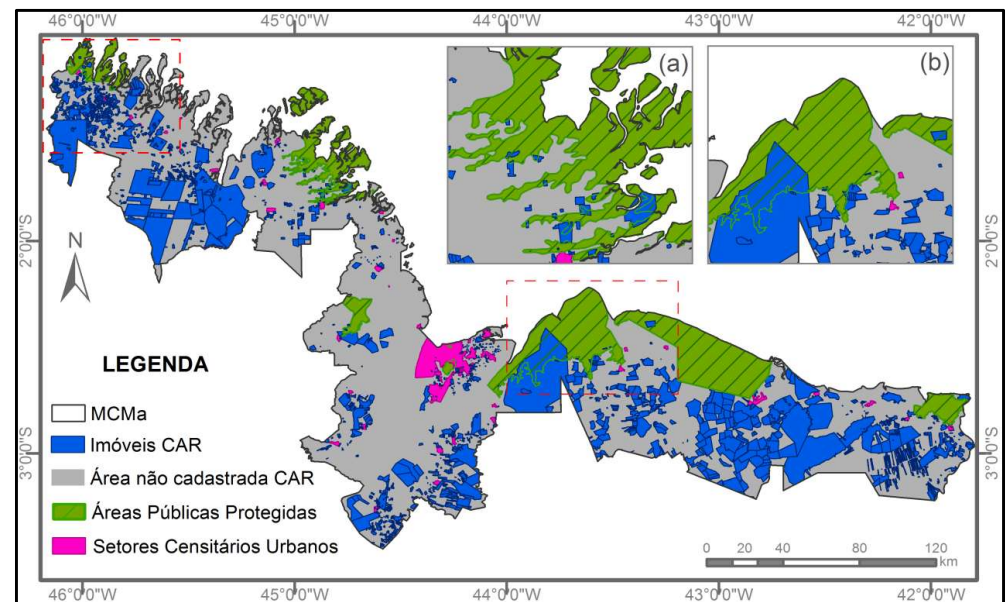

Figura 4: Áreas dos imóveis dos CARs dos MCMa, áreas protegidas e urbanas.

Ainda quanto às Áreas Públicas Protegidas, foi aferido um conflito de registros com as áreas dos imóveis em torno de 33.200ha no objeto em estudo. Inconformidade exemplificada pela figura 4 na Resexs Federais de Cururupu e Arapiranga-Tromaí (a) e no PARNA dos Lençóis Maranhenses e Resex Federal Baía do Tubarão (b). Dissonância em atenção à Lei Federal 9.985/2000, Art. 11 e 18, que define como áreas de domínio público e, quando com áreas particulares no interior, com devida desapropriação como dispõe a lei (BRASIL, 2000). Além das informações e resultados discutidos acima, a tabela 2 apresenta a síntese do cruzamento de informações disponíveis nos registros dos imóveis pelo SFB e àquelas colhidas em outros órgãos.

Tabela 2: Análise comparativa entre informações declaradas no SiCAR e de fontes independentes (MMA, IBGE, ANA, Embrapa, SEMA/MA).

\begin{tabular}{|c|c|c|c|c|}
\hline $\begin{array}{c}\text { Variáveis } \\
\text { ambientais }\end{array}$ & $\begin{array}{c}\text { Dados } \\
\text { CAR (ha) }\end{array}$ & $\begin{array}{c}\text { Dados } \\
\text { independentes (ha) }\end{array}$ & $\begin{array}{c}\text { Conformidade } \\
\text { espacial }(\%)^{1} \\
\end{array}$ & $\begin{array}{c}\text { Não } \\
\text { declarado (\%) } \\
\end{array}$ \\
\hline Área passível de cadastramento ${ }^{2}$ & $948.486,565$ & $2.969 .718,842$ & $32 \%$ & $68 \%$ \\
\hline APP de áreas declividade $>45^{\circ}$ & $\sim 0$ & $\sim 0$ & $100 \%$ & - \\
\hline APP de áreas com elevação > 1800 m & 0 & 0 & $100 \%$ & - \\
\hline Manguezal & $\begin{array}{l}9.782,634 \\
3.782,007 \\
\end{array}$ & $\begin{array}{c}801.066,458 \\
159.590,870^{3}\end{array}$ & $2,4 \%$ & $\sim 94 \%$ \\
\hline Restinga & $\begin{array}{l}15.367,051 \\
15.004,198 \\
\end{array}$ & $\begin{array}{c}857.414,929 \\
286.089,037^{3} \\
\end{array}$ & $5,2 \%$ & $\sim 94 \%$ \\
\hline APP de cursos d'água (Hidrografia ${ }^{4}$ ) & $19.114,107^{3}$ & $\begin{array}{c}53.908,285 \\
14.504,322^{3}\end{array}$ & $17 \%$ & $83 \%$ \\
\hline
\end{tabular}

Legenda: ${ }^{1}$ Com base apenas na sobreposição das áreas no cruzamento; ${ }^{2}$ Algumas áreas da União e do Estado não foram contempladas por indisponibilidade de dados espacializados; ${ }^{3}$ Área considerando apenas a soma dentro dos imóveis cadastrados; e ${ }^{4}$ Considerando a menor faixa de APP para cursos d'água da Lei Federal 12.651/2012 (30 metros).

Quanto aos dados de declividade superior a $45^{\circ}$, apenas um registro declarou essa informação, sendo uma área de 0,05ha $\left(522 \mathrm{~m}^{2}\right)$. Todavia, devido à geometria retangular, apresenta fortes indícios de ser um equívoco do operador durante o cadastro. Presumidamente devido ao relevo, por se tratar de uma área de planície litorânea como pontuado por Bandeira (2013) e Galvão (1995), resultado que apresentou 
conformidade com a realidade da área. Outra comparação que apresentou mesma aderência, devido à geomorfologia, foi de áreas com altitude superior a 1800 metros, não sendo objeto na MCMa (figura 5).

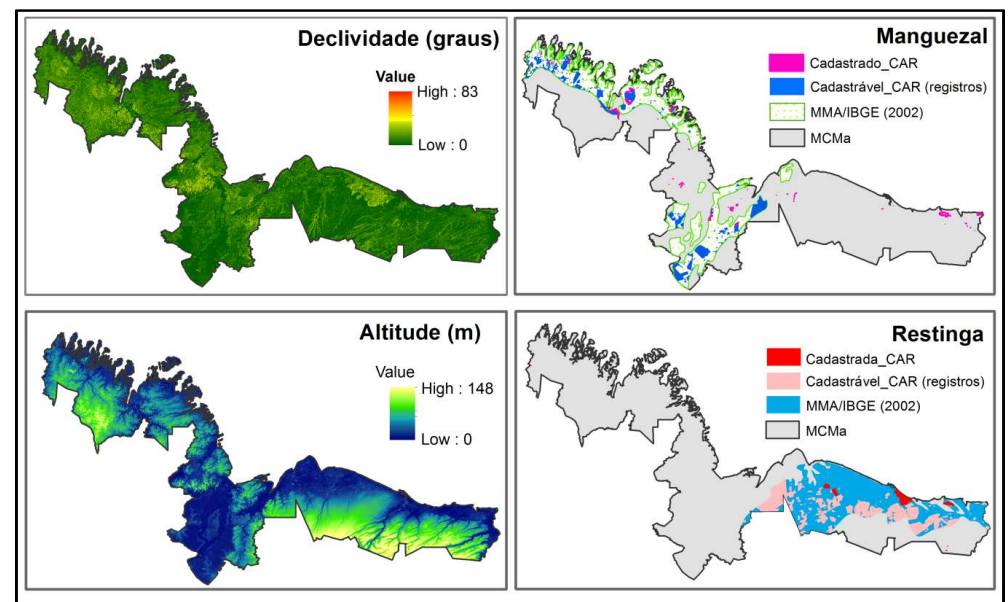

Figura 5: Cotejo espacial dos dados CAR da ZCMa e de órgãos ambientais

Já quanto à fitofisionomia (tabela 2 e figura 5), a conformidade espacial para áreas de manguezais e restingas foi muito baixa, menores que $6 \%$. Valor esse considerando apenas às áreas dentro dos imóveis registrados. Um ponto a ser considerado na discussão é a escala e a precisão dos dados do MMA/IBGE de manguezais e restingas utilizados, haja vista que sugerem superestimação da realidade.

Contudo, conforme publicação do Atlas dos Manguezais do Brasil (ICMBIO, 2018), o Estado do Maranhão possui uma área de manguezal na ordem de 505,5 milhões de ha (36\% dos manguezais nacionais), um número muito expressivo e que ficou muito remoto da área declarada e declarável nos imóveis CAR (tabela 2), corroborando para baixa carência destacada nos resultados.

E isso afeta na consistência dos dados diante dos objetivos do CAR, que é, em síntese, construir um banco de dados de informações ambientais para melhor gestão pública dessas áreas; usando como subsídios em estudos de planejamento e regularização de imóveis. A figura 6 apresenta algumas adversidades encontradas durante o cruzamento de dados para as APPs de cursos d'água na área em estudo. Ressaltando que na geração das informações de APPs com a hidrografia da ANA, fora utilizado o critério de faixa de APP menos rigoroso do Código Florestal, qual seja, de $30 \mathrm{~m}$ para cursos d'águas com largura inferior a $10 \mathrm{~m}$.

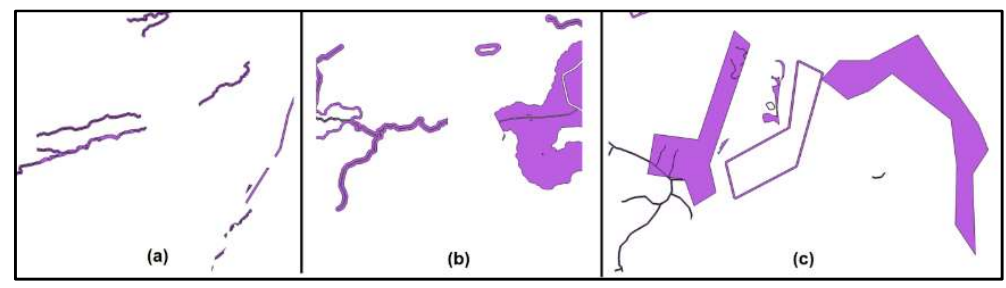

Figura 6: Entraves evidenciados nas faixas de APP declaradas no CAR.

Dentre os principais entraves, os mais frequentes foram fracionamento e descontinuidades nas faixas de APP, ou seja, um proprietário declarou sua APP, enquanto o proprietário vizinho não fez o mesmo; ainda em respeito à análise circunvizinha, diferentes faixas de largura de APP para um mesmo curso d'água com curta distância (b); e áreas declaradas como APP de geometria duvidosa.

Em relação ao cotejo entre a faixa de APP gerada com hidrografia da ANA (buffer de 30 metros) com 
as áreas constantes nos registros CAR, apenas 17\% (tabela 2) obtiveram aderência. A contraponto, é sabido das dificuldades de se utilizar representações vetoriais de cursos d'água superficiais fidedignos à realidade, uma vez que geralmente essas malhas tendem a generalizar ou se suavizar durante seu processo de geração.

\section{CONSIDERAÇÕES FINAIS}

O CAR é uma ferramenta de gestão pública com objetivo robusto e inovador, a nível nacional, para contribuir num planejamento articulado e de uso sustentável dos recursos ambientais. Todavia, apresenta alguns entraves importantes que devem ser observados e corrigidos, particularmente em áreas sensíveis e de forte susceptibilidade a impactos ambientais, como no caso de áreas costeiras, composta por mosaicos de diferentes ambientes, tal como os manguezais.

Vale destacar que o objetivo da pesquisa não foi validar as informações ambientais declaradas na plataforma do SiCAR, mas sim analisar - numa perspectiva macro dos MCMa - a consistências desses dados, se apresentam indícios de aderência a outros dados anteriormente divulgados, assim como os entraves gerados na fase de cadastramento. A validação dos registros CAR será realizada no seu Módulo de Validação. Fase esta que, face aos indícios dos resultados aqui apresentados, apontam alguns desafios para o órgão ambiental estadual. Associado ainda a carência no quadro técnico destes órgãos, em termos numéricos e com capacidade operacional, corroborará ainda mais na morosidade, impactando na eficiência e objetivo da ferramenta.

\section{REFERÊNCIAS}

ABIOVE. Associação Brasileira das Indústrias de Óleos Vegetais. Informativo digital $\mathbf{n . 1 4 2 / 2 0 1 6}$ fevereiro: a dois meses do prazo final, inscrições no CAR avançam em todo o País. São Paulo: ABIOVE, 2016.

BANDEIRA, I. C. N.. Geodiversidade do Estado do Maranhão: Programa Geologia do Brasil, Levantamento da Geodiversidade. Teresina: CPRM, 2013.

BRASIL. Decreto Federal n.5300 de 7 de dezembro de 2004. Regulamenta a Lei no 7.661, de 16 de maio de 1988, que institui o Plano Nacional de Gerenciamento Costeiro - PNGC, dispõe sobre regras de uso e ocupação da zona costeira e estabelece critérios de gestão da orla marítima, e dá outras providências. Brasília: DOU, 2004.

BRASIL. Decreto Federal n.7830 de 17 de outubro de 2012. Dispõe sobre o Sistema de Cadastro Ambiental Rural, o Cadastro Ambiental Rural, estabelece normas de caráter geral aos Programas de Regularização Ambiental, de que trata a Lei no 12.651 , de 25 de maio de 2012, e dá outras providências. 2012b. Brasília: DOU, 2012.

BRASIL. Lei Federal n.12651 de $\mathbf{2 5}$ de maio de 2012. Dispõe sobre a proteção da vegetação nativa; altera as Leis n.6.938, de 31 de agosto de 1981, 9.393, de 19 de dezembro de 1996, e 11.428, de 22 de dezembro de 2006; revoga as Leis n.4771, de 15 de setembro de 1965, e 7754, de 14 de abril de 1989, e a Medida Provisória n.2166-67, de 24 de agosto de 2001; e dá outras providências. 2012a. Brasília: DOU, 2012.
BRASIL. Lei Federal n.7661 de 16 de maio de 1988. Institui o Plano Nacional de Gerenciamento Costeiro e dá outras providências. Brasília: DOU, 1988.

BRASIL. Lei Federal n.9985 de 18 de julho de 2000. Regulamenta o art. 225, § 10, incisos I, II, III e VII da Constituição Federal, institui o Sistema Nacional de Unidades de Conservação da Natureza e dá outras providências. Brasília: DOU, 2000.

BRASIL. Medida Provisória n.844 de $\mathbf{1 4}$ de junho de 2019. Altera a Lei no 12.651 , de 25 de maio de 2012, que dispõe sobre a proteção da vegetação nativa e dá outras providências. Retira prazo para inscrição de propriedades no CAR. Brasília: DOU, 2019.

BRUGNARA, E.; SANTOS, B. D. C.; SOUSA, S. C. C.; BUTTURRI, W.; SILGUEIRO, V. F.; WOJCIECHOWSKI, J. C.. Mapeamento das classes do Cadastro Ambiental Rural (CAR) em municípios do território portal da Amazônia. Alta Floresta: ICV, 2016.

EL-ROBRINI, M.; MARQUES JUNIOR, V.; SILVA, M. M. A.; ELROBRINI, H. S.; FEITOSA, A. C.; TAROUCO, J. E. F.; SANTOS, J. H.; VIANA, J. R.. Maranhão. Brasília: MMA, 2006.

GALVÃO, R.. Introdução ao conhecimento da área maranhense abrangida pelo plano de valorização econômica da Amazônia. Revista Brasileira de Geografia, n.3, p.3-63, 1995. 
ICMBIO. Instituto Chico Mendes de Conservação da Biodiversidade. Atlas dos manguezais do Brasil. Brasília: ICMBio, 2018.

INOVACAR. Iniciativa de Observação, Verificação e Aprendizagem do CAR e regularização ambiental. III Relatório de Acompanhamento, março de 2016: A implementação do Cadastro Ambiental Rural (CAR) e do Programa de Regularização Ambiental (PRA) nos estados brasileiros. Cuiabá: INOVACAR, 2016.

INOVACAR. Iniciativa de Observação, Verificação e Aprendizagem do CAR e regularização ambiental. Relatório 2015. Cuiabá: INOVACAR, 2015.

INOVACAR. Iniciativa de Observação, Verificação e Aprendizagem do CAR e regularização ambiental. Relatório 2014. Cuiabá: INOVACAR, 2014.

MARANHÃO. Lei Estadual n.5405 de 8 de abril de 1992. Institui o Código de Proteção de Meio Ambiente e dispõe sobre o Sistema Estadual de Meio Ambiente e o uso adequado dos recursos naturais do Estado do Maranhão. São Luís: DOE, 1992.

MARTINS, M. B.; OLIVEIRA, T. G.. Amazônia Maranhense: Diversidade e Conservação. Belém: MPEG, 2011. MMA. Ministério do Meio Ambiente. Maranhão: Municípios Costeiros. Brasília: MMA, 2015.
PANTOJA, M. A. L.; NASCIMENTO, D. N. O.; AGUIAR, E. S.; BEZERRA, K. C. A.; DIAS, Y. N.; PEREIRA, B. W. F.. Uso de SIGs para análise de informações do Cadastro Ambiental Rural no município de Igarapé-Açu. In: SIMPÓSIO BRASILEIRO DE SENSORIAMENTO REMOTO, 17. Anais. João Pessoa: 2015.

PINHEIRO, J. M.. Análise do sistema costeiro da llha do Maranhão. In: SIMPÓSIO NACIONAL DE GEOMORFOLOGIA, 4. Anais. São Luís: 2002.

SFB. Sistema Florestal Brasileiro. CAR: Boletim Informativo, dados até 30 de abril de 2019. Brasília: SFB, 2019.

STRAPASSON JUNIOR, M. J.. Avaliação do cadastro ambiental rural e diagnóstico da percepção florestal dos proprietários na região metropolitana norte de Curitiba. Monografia (Graduação em Engenharia Florestal) Universidade Federal do Paraná, Curitiba, 2016.

TEIXEIRA, S. G.; SOUZA FILHO, P. W. M.. Mapeamento de ambientes costeiros tropicais (Golfão Maranhense, Brasil) utilizando imagens de sensores remotos orbitais. Revista Brasileira de Geofísica, v.27, n.1, p.69-82, 2009.

TUPIASSU, L.; GROS-DESORMAUX, J.; CRUZ, G. A. C.. Regularização Fundiária e Política Ambiental: Incongruências do Cadastro Ambiental Rural no Estado do Pará. Revista Brasileira de Políticas Públicas, Brasília, v.7, n.2, p.187-202, 2017.

A CBPC - Companhia Brasileira de Produção Científica (CNPJ: 11.221.422/0001-03) detém os direitos materiais desta publicação. Os direitos referem-se à publicação do trabalho em qualquer parte do mundo, incluindo os direitos às renovações, expansões e disseminações da contribuição, bem como outros direitos subsidiários. Todos os trabalhos publicados eletronicamente poderão posteriormente ser publicados em coletâneas impressas sob coordenação da Sustenere Publishing, da Companhia Brasileira de Produção Científica e seus parceiros autorizados. Os (as) autores (as) preservam os direitos autorais, mas não têm permissão para a publicação da contribuição em outro meio, impresso ou digital, em português ou em tradução. 